\title{
The effect of addition of MWCNTs nanoparticles to CryoMQL conditions on tool wear patterns, tool life, roughness and temperature in turning of Ti-6Al-4V.
}

Ben Wang ( $\square$ wangben211@163.com )

Shenyang Aerospace University

Xianjun Kong

\section{Research Article}

Keywords: Nanofluid, MWCNTs, tool wear, surface roughness/topography

Posted Date: February 7th, 2022

DOI: https://doi.org/10.21203/rs.3.rs-1322956/v1

License: (c) (i) This work is licensed under a Creative Commons Attribution 4.0 International License.

Read Full License 


\section{Abstract}

In recent years, advancements in the field of nanotechnology have actively been reflected in the manufacturing industry, particularly in the production of aviation components, ships, and medical devices. However, titanium alloys have low thermal conductivity, making them difficult to cut at high temperatures. The traditional processing method is not only inefficient, but can also cause serious harm to the environment and operators. In this paper, multi-walled carbon nanotubes were used as additives to disperse into degradable vegetable oil as a green cutting fluid. This green cutting fluid was cooled to analyze the processing of a titanium alloy $\left(\mathrm{LN}_{2}+\right.$ Nano-MQL $\left.(0.6 \%)\right)$. Cutting experiments were carried out under dry, MQL, $\mathrm{LN}_{2}, \mathrm{LN}_{2}+\mathrm{MQL}$, and $\mathrm{LN}_{2}+$ Nano-MQL $(0.6 \%)$ conditions. The temperature of the machining area, tool wear process, tool wear mechanism, surface roughness, and surface morphology were studied. The results show that the cutting-zone temperature is reduced by $65.1 \%$, the tool life is prolonged by $30 \%$, and the surface roughness is reduced by $48.1 \%$ under $\mathrm{LN}_{2}+$ Nano-MQL $(0.6 \%)$ in comparison to the dry condition. The cutting environment supported by MQL is conducive to inhibiting the formation of craters. Element detection confirmed that the tool coating was well protected under the condition of $\mathrm{LN}_{2}+$ Nano-MQL $(0.6 \%)$. In addition, the tool nose wear is small under the $\mathrm{LN}_{2}+\mathrm{MQL}$ and $\mathrm{LN}_{2}+$ Nano-MQL $(0.6 \%)$ conditions.

\section{Introduction}

Although titanium alloys have very complex extraction, melting, and processing conditions, they have received significant amounts of attention for the manufacturing of aviation components, ships, and medical devices. However, their lower thermal conductivity, lower Young's modulus, and the adhesion of titanium to tools at higher temperatures make titanium-based alloys difficult to cut ${ }^{[1]}$. In heat-resistant alloy processing, traditional processing technologies have low efficiencies. The productivity and sustainability of conventional heat-resistant alloy processing technologies are not adequate. Environmentally friendly government regulations are also driving the manufacturing industry to adopt sustainable processing technologies, rather than inefficient traditional ones ${ }^{[2]}$. The health and safety of workers is a key social factor that determines the sustainability of machining technology. Researchers have worked to develop alternative processing strategies to make these technologies safer, healthier, and more sustainable ${ }^{[3]}$.

MQL systems are an effective alternative to traditional lubrication methods. These systems spray oil droplets and pressurize air through a nozzle onto the cutting area. The oil droplets provide sufficient lubrication at the tool-chip and tool-workpiece interface to reduce friction and heat generation in the cutting zone ${ }^{[4]}$. In addition, they evaporate in a short time without leaving any residue on the workpiece or tool. Dhar et al. ${ }^{[5]}$ processed AISI-1040 steel using uncoated carbide inserts under MQL conditions. Two main performance characteristics -the chip formation and cutting temperature-were analyzed under flooding, drying, and MQL conditions. The results show that MQL is the best processing method at higher cutting speeds and lower feed rates. Khan et al. ${ }^{[6]}$ studied the effects of MQL, flooding, and dry cutting on 
the turning process of AISI 9310 alloy steel. Compared with flooding and dry cutting, MQL has a lower cutting temperature, lower tool wear, and favorable chip characteristics.

Although MQL seems to provide enough lubrication, the cooling effect of the processing area is insufficient under heavy processing conditions. The high heat generated during chip removal cannot be controlled, which significantly reduces the processing efficiency. Low-temperature cooling is a preferred cooling method for thermal control. In general, cryogenic cooling involves transporting a refrigerant gas in the liquid form to the tool-workpiece interface using a nozzle $\mathrm{e}^{[7]}$. $\mathrm{LN}_{2}$ is one of the most popular coolants in machining operations. It is lighter than air and can diffuse into the surroundings after use. This reduces the need for maintenance, post-processing cleaning, and processing requirements ${ }^{[8]}$. Lowtemperature cooling has been considered to be a green production technology and is one of the leading cooling methods for sustainable manufacturing ${ }^{[9]}$. Islam et al. ${ }^{[10]}$ compared dry cooling, flood cooling, and low-temperature cooling in terms of the processing of EN24 steel. The results show that lowtemperature cooling has good effects on the surface roughness, cutting force, and tool wear. Dhananchezian et al. ${ }^{[11]}$ compared low-temperature cooling with conventional cooling during the processing of Ti-6Al-4V alloys. The results show that low-temperature cooling reduces the cutting force by $35-42 \%$. Further, the cutting temperature decreased by $61-66 \%$, the surface roughness decreased by $36 \%$, and the tool wear decreased by $27-39 \%$. Previous studies have confirmed that, for titanium alloy processing, the MQL and low-temperature environments have exhibited better results than flood and dry cutting. However, the low-temperature environment only provides a cooling effect and has insufficient lubrication. In contrast, MQL mainly provides lubrication and is usually ineffective under heavy processing conditions, especially for titanium alloy processing. Therefore, a large number of researchers have explored mixed low-temperature and MQL conditions. Weinert et al. ${ }^{[12]}$ proved that cryogenic minimum quantity lubrication (CMQL) is a safe and effective cooling and lubrication method that can effectively replace conventional MQL technologies. Shokrani et al. applied CMQL to milling Ti-6Al-4V. They carried out milling experiments on a tool life model and compared the tool life under flood, MQL, low-temperature, and low-temperature micro-lubrication environments. The results show that, in a lowtemperature micro-lubrication environment, the tool life is 30 times longer than that of flood cooling ${ }^{[13]}$.

CMQL is a relatively new cooling lubrication method that has received significant research attention in recent years. It mainly provides lubrication and cooling for the processing area, improving its processing effect. This method employs two nozzles, one nozzle which sprays oil and the other sprays cryogenic liquid. However, during actual processing, the method of cooling by liquid nitrogen is the most effective. The minimum temperature of liquid nitrogen can reach $-196^{\circ}$, which can be further improved by lubrication. Under heavy processing conditions, the continuous high temperature in the processing area leads to the instantaneous evaporation of vegetable oil, which will weaken the lubrication effect in the processing area. Similarly, the coolant may not fully penetrate the microstructure of the tool-workpiece. Nanofluids have recently been used in MQL to increase the cooling and lubrication characteristics. In nanofluid technology, when additives (called nanolubricants or nanoparticles) are added to the base fluid, the physical, friction, and thermal properties of the cutting fluid improve, depending on the properties of 
the solid particles ${ }^{[14]}$. The most commonly used additives are molybdenum dioxide, boron nitride, alumina, silica, carbon nanotubes, titanium dioxide, copper oxide, graphite, etc ${ }^{[15-17]}$. In mechanical processing, although nanofluid-MQL has been studied for many years, the multi-walled carbon nanotube (MWCNTs) mixed nanofluid-MQL, which is a novel concept, has not been sufficiently researched.

In fact, few studies have focused on the surface roughness/surface morphology, tribological mechanism, tool wear, and wear mechanism of MWCNTs. In addition, the application of MWCNTs and vegetable oil combined with MQL is also rare. The main reasons for choosing MWCNTs as solid lubricants are their atomic structure and high specific surface area, along with their excellent thermal conductivity (of about $\left.3000-3500 \mathrm{~W} \cdot \mathrm{m}^{-1} \cdot \mathrm{K}^{-1}\right)$. Owing to these advantages, it is important to study the interactions between nano-cutting fluids and the tool and workpiece materials at low temperatures, and to establish a selection of sustainable processing titanium alloys (Ti-6Al-4V). Therefore, this study mainly analyzes the influence of the addition of MWCNTs in the low-temperature trace wetting (CMQL) system on the cutting performance indicators, including the tool wear and life, wear mechanism, the machining surface state (surface roughness and surface morphology), and the peak temperature of the cutting zone when turning titanium alloys (Ti-6Al-4V) with a titanium nitride coated carbide cutting blade. Therefore, five different experimental environments were designed to facilitate a comparison (Dry, MQL, $L N_{2}, \mathrm{LN}_{2}+\mathrm{MQL}$, and $\mathrm{LN}_{2}$ + Nano-MQL (0.6\%)). In these comparisons, the addition of $0.6 \%$ MWCNTs on the basis of lowtemperature minimum lubrication is analyzed.

\section{Materials And Methods}

\subsection{Experimental material}

In the experimental study, Ti-6Al-4V titanium alloy was used as the workpiece, with dimensions of 50 $\mathrm{mm} \times 200 \mathrm{~mm}$. The chemical composition of Ti-6Al-4V for turning experiments is shown in Table 1. The coated cemented carbide tool DCMT11T304-SMIC907, produced by ISCAR, was used for cutting experiments. Canola oil was selected as the base oil, with superior lubricating ability. In addition, it is environmentally friendly, naturally biodegradable, and free of chlorine and heavy metals. MWCNTs are different types of carbon nanotubes formed when multiple carbon nanotubes intertwine with each other. Figure 1 shows the microstructure of MWCNTs at different magnifications under an electron microscope. Detailed information regarding MWCNTs is given in Table 2. Although the number of nanotubes in MWCNTs is at least three, it can also reach 20. Their inner and outer diameters are between 2 and $50 \mathrm{~nm}$, respectively. Like single-walled nanotubes, they exhibit extraordinary electrical, thermal, and mechanical properties. For these reasons, functionalized MWCNTs were used as additives in this study. Before the preparation of nanofluids, preliminary experiments were carried out to determine the optimal proportion of nanoparticles, which was found to be $0.6 \%$ MWCNTs. This amount was then added to the base cutting fluid. A high-precision electronic balance (precision $=0.001 \mathrm{~g}$ ) was used to weigh the canola oil and carbon nanotubes. The solution mixture was stirred for $90 \mathrm{~min}$ at a speed of $1500 \mathrm{r} / \mathrm{min}$ with the help of a SUNNE (made in China) magnetic stirrer. Finally, the solution was dispersed using ultrasound for two 
hours. Finally, as shown in Figure 1, MWCNTs-rich nanofluids were obtained. In the mechanical processing experiment, to eliminate the potential deposition/agglomeration of MWCNTs, a fresh nanofluid mixture was used. The process for preparing nanofluids is shown in Figure 2.

Table 1

Chemical composition of Ti-6Al-4V

\begin{tabular}{|lllllllll|}
\hline Element & Al & $\mathbf{V}$ & $\mathbf{0}$ & $\mathbf{F e}$ & $\mathbf{C}$ & $\mathbf{H}$ & $\mathbf{N}$ & $\mathbf{T i}$ \\
\hline Weight(\%) & 5.72 & 4.1 & 0.1 & 0.004 & 0.02 & 0.005 & 0.022 & Balance \\
\hline
\end{tabular}

Table2 Details on multi-walled carbon nanotubes

\begin{tabular}{|l|ll|}
\cline { 2 - 3 } & Appearance & Black \\
\hline Black & $>98 \%$ \\
\hline Specific surface area & $\geq 190 \mathrm{~m}^{2} / \mathrm{g}$ \\
\hline Inside diameter & $3-5 \mathrm{~nm}$ \\
\hline Outside diameter & $8-15 \mathrm{~nm}$ \\
\hline Length & $5-15 \mu \mathrm{m}$ \\
\hline Density & $0.10 \mathrm{~g} / \mathrm{cm}^{3}$ \\
\hline & Carboxyl content & $1 \mathrm{mmol} / \mathrm{g}$ \\
\hline Preparation method & $\mathrm{CVD}$ \\
\hline
\end{tabular}

The NC lathe (CAK4085NJ) produced by the Shenyang Machine Tool Factory, China, was used in the machining experiment. The CNC machine tool spindle power is $7.5 \mathrm{~kW}$, the maximum speed is $2000 \mathrm{rpm}$, the hydraulic chuck diameter is $200 \mathrm{~mm}$, the turret knife number is 4, and the operating system is Fanuc. The micro-lubrication equipment provided by Sunair Fluid Technology (Shenzhen, China) Co., Ltd., was used in this study. In terms of low-temperature cooling, self-pressurized liquid nitrogen tank containers (produced by Jinan Olebo Scientific Instrument Co., Ltd., China) were used to accommodate the liquid nitrogen. The liquid nitrogen tank model was YDZ-30, with a geometric capacity of $32 \mathrm{~L}$ and a working pressure range of 0.02 to $0.09 \mathrm{MPa}$. It can provide the lowest possible temperature for the processing area $\left(-196^{\circ} \mathrm{C}\right)$. In addition, according to existing literature, maintaining a $30 \mathrm{~mm}$ nozzle distance and 45 degree nozzle angle provides the optimum performance ${ }^{[18]}$. Cutting temperatures were measured using an FLIR T630sc thermal infrared imager. The working temperature ranged from $-40^{\circ} \mathrm{C}$ to $600^{\circ} \mathrm{C}$ and the image acquisition frequency from $50 \mathrm{~Hz}$ to $200 \mathrm{~Hz}$. To guarantee the accuracy and reliability of the data, the temperature resolution of the equipment was less than $0.1^{\circ} \mathrm{C}$. First, the infrared thermal imager was 
adjusted to about one meter from the lathe. Second, the infrared thermal imager screen was adjusted until the tool and workpiece contact area could be clearly seen on the screen. Finally, the computer identified the highest cutting temperature in the processing area. The TR240 surface roughness instrument was used to measure the average surface roughness under each cutting condition. By rotating the workpiece by $40^{\circ}$, nine measurement values under each condition were obtained, and then the arithmetic average of these values was taken. In addition, to obtain the three-dimensional surface morphology and two-dimensional surface image of the machined surface, three-dimensional optical profiler equipment (Bruker Contour GTK 3D) was used. Finally, the tool wear was analyzed in detail through field emission scanning electron microscopy (ZEISS). In addition, energy dispersive X-ray (EDX) analysis was carried out on the tool surface to accurately analyze the chemical composition of the cutting zone.

\subsection{Experimental methodology}

The cutting conditions of the turning experiment were a constant cutting speed $(\mathrm{V})$ of $100 \mathrm{~m} / \mathrm{min}$, a feed speed (f) of $0.1 \mathrm{~mm} / \mathrm{rev}$, and a cutting depth $\left(a_{p}\right)$ of $0.5 \mathrm{~mm}$. The five processing environments were dry, $M Q L, L N_{2}, L N_{2}+M Q L$, and $L N_{2}+$ Nano-MQL (0.6\%). The pressure of the air compressor was 10 bar. According to ISO 3685 , the time when the flank wear value reaches $0.6 \mathrm{~mm}$ is the effective life of the tool[19]. In this study, the maximum wear VBmax $=0.6 \mathrm{~mm}$ was used as the evaluation standard, and two different methods were used to evaluate tool wear. The first method involved comparing the tool wear (VBmax) under all machining conditions after cutting for $8 \mathrm{~min}$. The other method involved continuing the test on the basis of previous test results until the tool wear reached the wear standard value of 0.6 $\mathrm{mm}$, and then comparing the processing time (tool life) under different conditions. Each experiment was carried out with new tools and was repeated twice. The wear of the cutting tools was measured using a VMX-2000C ultra-large depth-of-field optical three-dimensional microscope. First, the photos of the tool flank were captured; then, two parallel lines were drawn to limit the maximum tool wear width, and the maximum tool wear was calculated. The cutting conditions are shown in Table 3, and the entire experimental device is shown in Figure 2.

Table3 Cutting conditions for turning operations. 


\begin{tabular}{|ll|}
\hline Base oil & Canola \\
\hline Machining conditions & Dry, MQL, LN $\mathrm{LN}_{2} \mathrm{LN}_{2}+\mathrm{MQL}, \mathrm{LN}_{2}+\mathrm{Nano}-\mathrm{MQL}(0.6 \%)$ \\
\hline $\mathrm{V}$ & $100 \mathrm{~m} / \mathrm{min}$ \\
\hline $\mathrm{F}$ & $0.1 \mathrm{~mm} / \mathrm{rev}$ \\
\hline $\mathrm{A}_{\mathrm{p}}$ & $0.5 \mathrm{~mm}$ \\
\hline $\mathrm{P}_{\text {air }}$ & $10 \mathrm{bar}$ \\
\hline Machining times and $\mathrm{VB}_{\max }$ & $8 \mathrm{~min}$ and $0.6 \mathrm{~mm}$ \\
\hline
\end{tabular}

\section{Results And Discussion}

\subsection{Peak temperature in the cutting zone}

During the cutting process, mechanical energy is mainly converted into thermal energy. The high temperature of the machining area has a direct impact on the dimensional accuracy, geometric accuracy, and surface integrity of the workpiece, especially the tool wear/life, which is crucial to the machinability ${ }^{[20]}$. Therefore, herein, the chip-tool interface temperature was measured by multiple sets of experiments, and the average temperature was calculated. The results are shown in Figure 3 , which shows that the most effective cooling/lubrication environment for the cutting temperature is $\mathrm{LN}_{2}+\mathrm{Nano}$ MQL $(0.6 \%)$. The dry cutting temperature is the highest; in dry cutting, due to the poor thermal conductivity of titanium alloys, the heat in the contact area between the tool and workpiece is not effectively released. Birmingham et al. compared several different machining environments by turning Ti$6 \mathrm{Al}-4 \mathrm{~V}$, and found that the cutting temperature in the dry cutting environment was the highest and increased with the processing time ${ }^{[21]}$. It is further observed that MQL has a lower cutting temperature than that of dry cutting. In fact, MQL provides lubrication for the processing area, where a small amount of cutting fluid $(10-100 \mathrm{ml} / \mathrm{h})$ is atomized with compressed air and sprayed into the cutting area as lubrication and cooling aerosol[22]. However, Li et al. ${ }^{[23]}$ pointed out that most vegetable oils contain a large number of unsaturated bonds with ideal low temperatures and ideal viscosity-temperature characteristics. This characteristic is attributed to the fact that fatty acids in vegetable oils usually form lubricating films through physical and chemical adsorption. Polar groups-such as $\mathrm{COOH}, \mathrm{COOR}$, and metal surface materials-are physically adsorbed by van der Waals (VDW) forces to form a physical adsorption film, which plays a role in lubrication and friction reduction. In fact, it is normal to provide cooling for MQL to lower the temperature. This is related to the cooling characteristics of liquid nitrogen. Effective cooling provided by liquid nitrogen has a more positive effect on the tool-chip and workpiecetool interface, resulting in a better cooling effect at low temperatures. Liquid nitrogen can also absorb heat and evaporate rapidly, forming a fluid gas protective layer between the chip and the blade, which acts as a lubricant ${ }^{[24]}$. However, it is worth noting that the temperature under $\mathrm{LN}_{2}$ and $M Q L+L N_{2}$ 
conditions is very similar. Previous studies have shown that the cryogenic environment has good cooling performance under high pressure and high-temperature processing conditions ${ }^{[25]}$. However, it is impossible to determine whether it has the same performance in terms of lubrication. In other words, in the low-temperature cooling process, the lubrication process is particularly weak for heavy processing conditions, so the efficiency is reduced. However, the temperature was further reduced by adding nanoparticles on the basis of $\mathrm{LN}_{2}+\mathrm{MQL}$. We know that the thermal conductivity of the base fluid increases when nanoparticles are added. Therefore, the atomic structure, high specific surface area, and excellent thermal conductivity of MWCNTs (about 3000-3500 W. $\mathrm{m}^{-1} \cdot \mathrm{K}^{-1}$ ) can help the cutting zone disperse more heat because it can improve the thermal conductivity and convective heat transfer coefficient of pure liquids ${ }^{[26,27]}$. Compared with the dry condition, the cutting temperature of $\mathrm{LN}_{2}+$ NanoMQL $(0.6 \%)$ decreased by $65.1 \%$. Similarly, compared with $\mathrm{LN}_{2}+\mathrm{MQL}$ (without nano additives), the cutting temperature of $\mathrm{LN}_{2}+$ Nano-MQL $(0.6 \%)$ reduced by $32.8 \%$.

\subsection{Tool wear progression}

\subsubsection{Flank wear}

Tool wear refers to the material loss in the contact area between the tool and workpiece material, which is the most basic metric for tool life. The cutting performance indexes, such as the surface roughness, cutting temperature, and surface integrity, are often related to tool wear and are directly affected by it. The wear itself is determined by the tool material, coating material, coating performance, and other parameters ${ }^{[28]}$. It can be seen from Figure 4 that the tool wear under dry conditions is the largest $(0.532$ $\mathrm{mm})$. The tool wear is significantly improved by providing lubrication for the machining area $(0.476 \mathrm{~mm})$. The chip removal amount in the cutting area and the effective spraying of oil mist droplets are possible through the nozzle and compression. They appear at the interface between the tool and the workpiece, forming a layer of processing fluid, which mainly reduces the friction between the tool and the workpiece. However, it is worth noting that low-temperature cooling is superior to micro lubrication for tool wear $(0.388 \mathrm{~mm})$. This may be due to the cooling effect of liquid nitrogen. This result directly contradicts that reported by Yıldırım et al ${ }^{[29]}$, who found that MQL is more effective than low-temperature machining in terms of reducing tool wear. Low-temperature cooling only helps to reduce the temperature of the cutting zone through forced convection, while the effect of the MQL method is two-fold. First, MQL's lubricants contain a layer of oil in the cutting area, which helps reduce friction. Secondly, due to the evaporation of oil droplets, MQL facilitates heat transfer. The difference between their results and the ones obtained herein could be because of the significant differences in the workpiece material properties. In addition, other factors-including the cutting conditions (cutting parameters and tool geometry) and nozzle anglecan also be determined. For these reasons, it is difficult to conduct a scientific and rigorous comparison between previous studies and this study. Although MQL provides lubrication for the contact area between the tool and the workpiece, effective heat dissipation is also very important for the machining area, which was confirmed by the findings of Khanna et al. Although MQL has a good lubrication ability, its cooling characteristics have certain disadvantages ${ }^{[30]}$. However, after cooling for MQL $\left(\mathrm{LN}_{2}+\mathrm{MQL}\right)$, the tool wear 
was significantly reduced, to $0.374 \mathrm{~mm}$. The effective cooling provided by liquid nitrogen has a more positive effect on the tool-chip and workpiece-tool interfaces, resulting in a better low-temperature cooling effect. In addition, MQL can promote chip removal from the cutting area and the low temperature can prevent the formation of built-up-edges on the tool, which also reduces tool wear ${ }^{[31]}$. However, the focus of this study is to improve the tool life by adding carbon nanotubes on the basis of lowtemperature micro lubrication ( $\left.L N_{2}+M Q L\right)$. It can be seen from Figure 4 that the tool wear under $\mathrm{LN}_{2}+$ Nano-MQL (0.6\%) treatment was significantly lower than that under $\mathrm{LN}_{2}+\mathrm{MQL}$. Titanium alloys have low thermal conductivities and heavy loads during processing, resulting in the rapid evaporation of vegetable oil. It has previously been mentioned that adding solid lubricants to MQL could significantly improve the process efficiency ${ }^{[32,33]}$.

\subsubsection{Tool life}

Extending the tool life is very important for improving process efficiency. However, in actual research, tool wear is not controlled, and it is difficult to estimate when a tool will reach a standard value of wear. To ensure that the VBmax values in each processing environment are consistent, the tool life is further explored on the basis of tests after turning for $8 \mathrm{~min}$. A wear value is obtained at each turning, and then compared with the standard value. Turning is repeated to approach the standard value until VBmax $=0.6$ $\mathrm{mm}$, finally giving the tool life under different processing environments. It is worth noting that, to ensure the continuity of the machining process, new blades should be used after each turning. Similarly, to obtain the VB value accurately, the processing time is shortened when the VB value is close to $0.6 \mathrm{~mm}$. $\mathrm{VB}=0.6 \mathrm{~mm}$ cannot be accurately obtained during actual processing. Therefore, to reduce the test error, the VB value is controlled within $0.003 \mathrm{~mm}$. A total of 41 cutting tools were used in this study. Table 4 shows the variation of tool wear VB with machining time under different machining conditions. It can be seen from Table 4 that the tool life in a dry cutting environment is the shortest $(527 \mathrm{~s})$, followed by that for MQL (560 s). However, an interesting phenomenon is that the tool life in $\mathrm{LN}_{2}$ and $L N_{2}+M Q L$ environments is very similar, at $600 \mathrm{~s}$ and $605 \mathrm{~s}$, respectively. This result is consistent with that for the cutting-zone temperature (3.1). It is likely that, with increases in the processing time, the tool wear is severe and the mechanical load increases, resulting in the lubrication effect of vegetable oil becoming not very obvious. However, the longest tool life ( $685 \mathrm{~s}$ ) was obtained by adding nanoparticles to lowtemperature micro lubrication ( $\left.\mathrm{LN}_{2}+\mathrm{MQL}\right)$. This indicates that the tool wear rate will decrease when using nanofluids. In comparison to the dry and $\mathrm{LN}_{2}+\mathrm{MQL}$ conditions, the tool life under $\mathrm{LN}_{2}+$ Nano-MQL $(0.6 \%)$ conditions increased by $30 \%$ and $13.2 \%$, respectively. Figure 5 shows the variation of tool wear with cutting time under five cutting conditions when cutting Ti6Al4V at $100 \mathrm{~m} / \mathrm{min}$. It can be observed from the figure that the wear trends of tool flanks in $\mathrm{LN}_{2}$ and $L N_{2}+M Q L$ environments are relatively similar, which is consistent with the relatively close tool life of the two. It is worth noting that the growth of tool wear under each processing condition is generally relatively stable.

Table4 The variation of tool wear with machining time under different machining environments. 


\begin{tabular}{|c|c|c|c|}
\hline Environment & Number & Time(s) & $\mathrm{VB}(\mathrm{mm})$ \\
\hline \multirow[t]{5}{*}{ Dry } & 1 & 480 & 0.523 \\
\hline & 2 & 500 & 0.566 \\
\hline & 3 & 520 & 0.593 \\
\hline & 4 & 525 & 0.598 \\
\hline & 5 & 527 & 0.601 \\
\hline \multirow[t]{6}{*}{ MQL } & 1 & 480 & 0.476 \\
\hline & 2 & 500 & 0.502 \\
\hline & 3 & 520 & 0.536 \\
\hline & 4 & 540 & 0.583 \\
\hline & 5 & 550 & 0.590 \\
\hline & 6 & 560 & 0.600 \\
\hline \multirow[t]{8}{*}{$\mathrm{LN}_{2}$} & 1 & 480 & 0.388 \\
\hline & 2 & 500 & 0.409 \\
\hline & 3 & 520 & 0.441 \\
\hline & 4 & 540 & 0.484 \\
\hline & 5 & 560 & 0.533 \\
\hline & 6 & 580 & 0.591 \\
\hline & 7 & 590 & 0.596 \\
\hline & 8 & 600 & 0.603 \\
\hline \multirow[t]{9}{*}{$\mathrm{LN}_{2}+\mathrm{MQL}$} & 1 & 480 & 0.374 \\
\hline & 2 & 500 & 0.397 \\
\hline & 3 & 520 & 0.430 \\
\hline & 4 & 540 & 0.477 \\
\hline & 5 & 560 & 0.529 \\
\hline & 6 & 580 & 0.588 \\
\hline & 7 & 590 & 0.592 \\
\hline & 8 & 600 & 0.599 \\
\hline & 9 & 605 & 0.603 \\
\hline
\end{tabular}




\begin{tabular}{|c|c|c|c|}
\hline Environment & Number & Time(s) & $\mathrm{VB}(\mathrm{mm})$ \\
\hline $\mathrm{LN}_{2}+$ Nano-MQL & 1 & 480 & 0.303 \\
\hline & 2 & 500 & 0.321 \\
\hline & 3 & 520 & 0.343 \\
\hline & 4 & 540 & 0.369 \\
\hline & 5 & 560 & 0.398 \\
\hline & 6 & 580 & 0.432 \\
\hline & 7 & 600 & 0.467 \\
\hline & 8 & 620 & 0.504 \\
\hline & 9 & 640 & 0.545 \\
\hline & 10 & 660 & 0.588 \\
\hline & 11 & 670 & 0.593 \\
\hline & 12 & 680 & 0.599 \\
\hline & 13 & 685 & 0.603 \\
\hline
\end{tabular}

\subsection{Tool wear mechanism}

To explore the main wear mechanism affecting tool wear, scanning electron microscopy (SEM) photographs of different regions of the worn tool were taken at the end of the wear process test. To accurately compare the wear mechanism under various cutting environments, the SEM images of tool wear were taken at the same cutting time, of 8 minutes, and at constant cutting parameters (i.e., a cutting speed of $100 \mathrm{~m} / \mathrm{min}$, feed rate of $0.1 \mathrm{~mm} / \mathrm{rev}$, and cutting depth of $0.5 \mathrm{~mm}$ ).

Further, crater wear (Figure 6) is the main form of tool failure. Kitagawa et al. ${ }^{[34]}$ pointed out that the chemical sensitivity of titanium alloys to tool materials as a response to elevated temperature-through the activation diffusion wear mechanism-is the main cause for crater wear on the rake face. Owing to the introduction of a sustainable cooling/lubrication environment into the system, some damage has been reduced or eliminated, but other forms of damage still exist in the insert. Figure 6 shows that crater wear was the most obvious and accompanied by cracks in dry cutting environments (Figure 6a). In a recent survey, Liang et al. ${ }^{[35]}$ also studied the same type of wear/damage for turning titanium alloys under dry conditions. Without lubrication and cooling, the cracks in the crater formed on the tool rake face are caused by stresses from the sudden increase in the chip load owing to the adhesion during cutting. Similarly, a small portion of crater wear was found under $\mathrm{LN}_{2}$ (Figure $6 \mathrm{~d}$ ). However, crater wear was not detected under the MQL, $\mathrm{LN}_{2}+\mathrm{MQL}$, and $\mathrm{LN}_{2}+$ Nano-MQL $(0.6 \%)$ conditions, as shown in Figure 6 (b, $\mathrm{c}$, and e). The results show that the cutting environments supported by MQL, such as MQL, LN ${ }_{2}+M Q L$, and 
$\mathrm{LN}_{2}+$ Nano-MQL, are conducive to inhibiting the formation of craters on the tool rake face. In other words, MQL is conducive to preventing crater wear on the tool rake face. However, it is worth noting that craters were found under $\mathrm{LN}_{2}$. This may be because $\mathrm{LN}_{2}$ can only provide a cooling effect, but the lubrication effect on the tool rake face is missing. However, this is not consistent with the results of previous MQL conditions under high loads and high temperatures. However, in this study, MQL and $\mathrm{LN}_{2}$ nozzles are always aligned to the tool rake face. Therefore, the sensitivity of the tool rake face to lubrication is much higher than that of the tool flank.

In addition, during the machining process, the excessive pressure on the cutting tool causes the workpiece material to attach or fuse with the cutting edge; the attached or fused materials then accumulate during processing. This phenomenon, called built-up edges (BUEs) in metal cutting operations, is often observed during titanium alloy processing. During the machining process of titanium alloys and other ductile materials, BUE can lead to changes in the cutting force and affect the surface roughness and tool wear process of the workpiece ${ }^{[36]}$. Unstable BUEs will exist on the cutting edge, changing the tool geometry and the optimal shear angle change during the cutting process, which reduces the cutting ability of the tool and increases the cutting force, vibration, and surface roughness. However, for the processing of titanium alloys, cooling and lubrication methods cannot completely eliminate BUEs. In other words, cooling and lubrication alone are not sufficient to eliminate the chemical activity of titanium alloys on tool surfaces. Further, in this study, BUEs are inevitable in all cutting environments. The interactions between BUEs and tools could be weakened-to some extent-by using lubrication and cooling methods; however, it cannot be completely eliminated. As can be seen from Figure 6, BUE formation under $\mathrm{LN}_{2}+\mathrm{MQL}$ and $\mathrm{LN}_{2}+$ Nano-MQL (0.6\%) systems is significantly lower than that in other cutting environments. This proves that the application of $\mathrm{LN}_{2}+\mathrm{MQL}$ and $\mathrm{LN}_{2}+$ Nano-MQL $(0.6 \%)$ reduces the temperature and provides convenient tool-chip interactions, thereby reducing the friction and BUE formation. As mentioned in section 3.1, the lowest temperature is obtained by providing cooling and lubrication for the processing area. In addition, SEM photographs also showed that tool nose wear occurred under the dry, MQL, and $\mathrm{LN}_{2}$ conditions; tool nose wear is generally caused by abrasive wear mechanisms ${ }^{[37]}$. On the other hand, the strength of the cobalt phase in cemented carbide tools decreases at high temperatures, which also leads to plastic deformation of the tool nose. However, the tool noses under the $\mathrm{LN}_{2}+\mathrm{MQL}$ and $\mathrm{LN}_{2}+$ Nano-MQL $(0.6 \%)$ conditions remained basically intact. In addition, it can be seen from the above discussion that, compared with other environments, the nose wear, crater wear, and BUEs of the tools under $\mathrm{LN}_{2}+\mathrm{MQL}$ and $\mathrm{LN}_{2}+$ Nano-MQL $(0.6 \%)$ are significantly reduced, but the difference between them is not obvious. However, an interesting phenomenon can be observed. $\mathrm{LN}_{2}+$ MQL with MWCNTs exhibited no damage to the tool coating. In comparison to other cutting environments, the protection of the tool coating under $\mathrm{LN}_{2}+$ Nano-MQL $(0.6 \%)$ conditions was the most effective. The boundary between the tool substrate and tool coating under dry, MQL, $L N_{2}$, and $\mathrm{LN}_{2}+\mathrm{MQL}$ conditions can be clearly seen from the electron microscope images in Figure 6. These results can also be obtained from EDS element detection, shown in Figure 7. Element detection showed that important elements, such as Co and W (the left side of the electron microscope image), were found in the tool 
substrate under dry, MQL, $\mathrm{LN}_{2}$, and $\mathrm{LN}_{2}+\mathrm{MQL}$ conditions; however, the $\mathrm{N}$ in the tool coating material was detected on the other side of the boundary (the right side of the electron microscope image). For the $\mathrm{LN}_{2}$ + Nano-MQL (0.6\%) condition, the element detection range was expanded, and no Co and W were found in the tool substrate. This shows that MWCNTs are conducive to protecting the coating material of the tool. Under the action of compressed air, MWCNTs will be transported to the processing area with vegetable oil, forming lubrication, thereby protecting the coating of the tool (Figure 8).

\subsection{Surface roughness}

Surface roughness $(\mathrm{Ra})$ is usually expressed as the average height change of peaks and valleys relative to the baseline. Many parameters affect the surface roughness; the lubrication/cooling environment is one of these. To compare the surface roughness values under different cutting environments, experiments must maintain constant cutting speeds, feed speeds, cutting depths, and nozzle flows.

Figure 9 shows the average surface roughness in different cutting environments; when the cutting speed is $100 \mathrm{~m} / \mathrm{min}$ and the feed rate is $0.1 \mathrm{~mm} / \mathrm{rev}$, the $\mathrm{LN}_{2}+$ Nano-MQL $(0.6 \%)$ condition leads to the minimum Ra value $(0.352 \mu \mathrm{m})$ in the turning process of the titanium alloy, followed by $\mathrm{LN}_{2}+\mathrm{MQL}, \mathrm{LN}_{2}$, MQL, and dry machining. For example, when the feed rate is $0.1 \mathrm{~mm} / \mathrm{rev}$ and the cutting speed is 100 $\mathrm{m} / \mathrm{min}$, the roughness value of dry machining is $0.487 \mu \mathrm{m}$, while an improvement of $22.9 \%$ was achieved using MQL. This improvement is $32.6 \%$ for $\mathrm{LN}_{2}, 34.2 \%$ for $\mathrm{LN}_{2}+\mathrm{MQL}$, and $48.1 \%$ for $\mathrm{LN}_{2}+$ Nano-MQL $(0.6 \%)$. It can be clearly seen from previous studies that when carbide inserts are used, the improvement rate of surface roughness differs under different cooling and lubrication methods ${ }^{[38,39]}$. In addition, an interesting result is obtained from this study in that $\mathrm{LN}_{2}$ is found to be superior to MQL in terms of reducing the surface roughness during titanium alloy turning. In addition, the surface roughness was not significantly improved after providing MQL support for $\mathrm{LN}_{2}$. These results are similar to those for tool wear discussed above. However, the surface roughness decreased significantly after the addition of MWCNTs under $\mathrm{LN}_{2}+\mathrm{MQL}$ conditions. According to the size, shape, hardness, and mechanical properties of nanoparticles in lubricating oil, some tribological enhancement mechanisms were reported in a previous study ${ }^{[40]}$. As shown in Figure 1, due to the tubular shape and atomic structure of MWCNTs, some mechanisms will play a more effective role in processing and provide a satisfactory effect on the interface when dispersed in the processing area ${ }^{[41]}$. As shown in Figure 10, the addition of MWCNTS under the condition of $\mathrm{LN}_{2}+\mathrm{MQL}$ will reduce the surface roughness, and its role can be summarized in terms of the following mechanisms ${ }^{[42]}$ :

1. In the surface repair mechanism (Figure $10(a)$ ), nanoparticles can settle in the pits on the surface of the workpiece, reducing the contact between the insert and the workpiece material by filling and repairing, thereby reducing friction and wear.

2. Nanoparticles form a protective film on the friction interface, as shown in Figure 10 (b).

3. In the rolling/sliding mechanism (Figure 10 (c)), nanoparticles can act as rotating bearings between the tool/workpiece interface to reduce contact, thereby reducing friction and wear. 
4. In the polishing mechanism shown in Figure 10 (d), due to the high hardness of the nanoparticles, they can effectively remove residues and help reduce the surface roughness of the workpiece.

\subsection{Surface topography}

Since the surface morphology directly affects the friction, wear, fatigue, and sealing performance of the parts, it is very important to study the surface morphology ${ }^{[43]}$. Figure 11 shows the $2 \mathrm{D}$ and $3 \mathrm{D}$ morphology images of the Ti-6Al-4V titanium alloy processed under different cutting environments at a $100 \mathrm{~m} / \mathrm{min}$ cutting speed and $0.1 \mathrm{~mm} / \mathrm{rev}$ feed rate. It can be seen from the figure that the valleys and peaks formed on the machined surface are clearly visible. Due to the nature of the cutting process, it is expected that the surface morphology of the processed material is irregular along the feed line. On the other hand, a more regular surface morphology is expected along the cutting speed line than along the feed line. However, this situation can be prevented by various external factors, such as vibration, tool wear, chip adhesion, and deformation caused by thermal damage $\mathrm{e}^{[44]}$. The red, blue, and green areas on the color map in Figure 11 show the height of the peak, the depth of the valley, and the nominal (favorable) position of the machined surface, respectively. Similarly, the maximum difference Rt between the peak and valley of the machined surface is shown at the rightmost red focus in Figure 11. By analyzing the 2D surface images in Figure 11, it can be seen that there are more red areas under dry and MQL conditions, and the machining marks (feed marks) are very obvious. When the 3D surface image is checked, it can be seen that the peak value under dry cutting is very high; under dry cutting conditions, the maximum difference between the peaks and valleys along the machined surface is greater than $17 \mu \mathrm{m}$. Under MQL, although the peaks gather more, the maximum difference between the peaks and valleys is $13.618 \mu \mathrm{m}$, which is smaller than that of dry cutting. It can also be seen in Figure 11 that the red area under $L N_{2}$ is significantly less than that under MQL and is replaced by a green area. The results obtained here are similar to their surface roughness results. When the existence of a nominal surface and the difference between hills and valleys were considered for evaluation, $\mathrm{LN}_{2}+$ Nano-MQL (0.6\%)-assisted machining achieved the best results in terms of the surface morphology and surface roughness. The maximum difference between the peak and valley was $3.33 \mu \mathrm{m}$, which is the smallest among all processing environments. This can be attributed to the fact that MWCNTs nanoparticles added in the cutting oil can significantly improve the friction and wear mechanism of the tool-chip interface (including the repair effect, protective film effect, rolling effect, and polishing effect), so as to obtain a better surface morphology. It is believed that MWCNTs solid nanoparticles added to the cutting oil can also significantly reduce the thermal degradation of the surface with high thermal carrying capacity, further improving the surface morphology ${ }^{[45]}$. In fact, as mentioned above, the minimum temperature obtained by nanofluid-MQL supports this result.

\section{Conclusion}

The cutting temperature, tool wear and life, tool wear mechanism, surface roughness, and surface morphology of TiAIN cutting tools for turning titanium alloy ( Ti-6Al-4V) under different cutting environments were studied herein. During the experiment, five different cutting environments (dry, MQL, 
$\mathrm{LN}_{2}, \mathrm{LN}_{2}+\mathrm{MQL}$, and $\mathrm{LN}_{2}+$ Nano-MQL $\left.(0.6 \%)\right)$ were compared. A cutting speed of $100 \mathrm{~m} / \mathrm{min}$ and a feed rate of $0.15 \mathrm{~mm} / \mathrm{rev}$ were used as the inputs of the turning experiment. The results of this study are summarized as follows:

1. Due to the addition of nanoparticles, the temperature under $\mathrm{LN}_{2}+$ Nano-MQL (0.6\%) conditions decreased significantly $\left(123^{\circ} \mathrm{C}\right)$. In comparison to dry cutting $\left(352^{\circ} \mathrm{C}\right)$, the peak temperature of the cutting zone decreased by $65.1 \%$ after adding MWCNTs. Due to the high thermal conductivity of MWCNTs, NanoMQL can replace pure MQL, especially under heavy machining conditions.

2. The flank wear under the $\mathrm{LN}_{2}+$ Nano-MQL $(0.6 \%)$ condition was the smallest, where VB $\max =0.303$ $\mathrm{mm}$, followed by that for $\mathrm{LN}_{2}+\mathrm{MQL}(\mathrm{VB} \max =0.374 \mathrm{~mm}), \mathrm{LN}_{2}(\mathrm{VB} \max =0.388 \mathrm{~mm}), \mathrm{MQL}(\mathrm{VB} \max =$ $0.476 \mathrm{~mm}$ ), and dry (VB max $=0.523 \mathrm{~mm}$ ) conditions. On the other hand, the tool life under the $\mathrm{LN}_{2}+$ Nano-MQL $(0.6 \%)$ condition was the longest (685 s), which is $30 \%$ higher than that of dry cutting (527 s). 3. BUEs are inevitable in all cutting environments. Craters were found on the tool under both dry and $\mathrm{LN}_{2}$ conditions, and the cutting environment supported by MQL was conducive to inhibiting the formation of craters on the tool rake face. In addition, the nose wear of the tool mainly occurred in dry, MQL, and $\mathrm{LN}_{2}$ conditions. However, under $\mathrm{LN}_{2}+$ Nano-MQL $(0.6 \%)$ conditions, not only was the nose wear very small, but no coating was removed on the rake face of the tool under MWCNTs-based nanofluid-MQL.

4. The average surface roughness $(\mathrm{Ra})$ under the dry, pure MQL, $\mathrm{LN}_{2}, \mathrm{LN}_{2}+\mathrm{MQL}$, and $\mathrm{LN}_{2}+$ Nano-MQL $(0.6 \%)$ conditions were $0.678 \mu \mathrm{m}, 0.523 \mu \mathrm{m}, 0.457 \mu \mathrm{m}, 0.446 \mu \mathrm{m}$, and $0.352 \mu \mathrm{m}$, respectively. In comparison to dry cutting, the surface roughness under the $\mathrm{LN}_{2}+$ Nano-MQL $(0.6 \%)$ condition is reduced by about $48.1 \%$.

5. It can be seen from the surface morphology results that the machining traces (feed traces) are quite obvious under dry and MQL conditions, while these traces are significantly reduced under $\mathrm{LN}_{2}$ conditions. The peak is highest during dry cutting; however, under $\mathrm{LN}_{2}+$ Nano-MQL $(0.6 \%)$ conditions, not only was the peak height significantly reduced, but the peak aggregation was also reduced. In addition, the study also concluded that $\mathrm{LN}_{2}+$ Nano-MQL $(0.6 \%)$ conditions exhibited the best performance in terms of surface morphology because MWCNTs added to the cutting oil could significantly improve wear and heat transfer.

\section{Declarations}

\section{Acknowledgments}

This study was fnancially supported by the National Natural Science Foundation of China (NSFC) (Grant NO. 51875367), LiaoNing Revitalization Talents Prograrn (Grant NO. XLYC2007011), Natural Science Foundation of Liaoning Province (Grant No. 2020- MS-223), China Postdoctoral Science Foundation (Grant No. 2020M670790) .

\section{Competing Interests}


The authors declare that they have no known competing financial interests or personal relationships that could have appeared to influence the work reported in this paper.

\section{Availability of data and material}

Not applicable (Secret information)

\section{Authors' Contributions}

Ben Wang: conceptualization, methodology, and writing (review and editing)

Quanwei Yang: formal analysis and writing (original draft)

Jiawei Deng: investigation

Yaohui Zheng: supervision

Xianjun Kong: validation

\section{References}

1. Li R, Shih AJ (2007) Tool Temperature in Titanium Drilling. J Manuf Sci Eng 129(4):740-749

2. Yıldırım ÇV, Sarıkaya M (2019) The effect of addition of hBN nanoparticles to nanofluid-MQL on tool wear patterns, tool life, roughness and temperature in turning of Ni-based Inconel 625 . Tribol Int 134:443-456

3. Umbrello D, Pu Z, Caruso S, Outeiro JC, Jayal AD, Dillon OW, Jawahir IS (2011) The effects of Cryogenic Cooling on Surface Integrity in Hard Machining. Procedia Eng 19:371-376

4. Etinda HA, lek A, Uak N (2020) The effects of CryoMQL conditions on tool wear and surface integrity in hard turning of AISI 52100 bearing steel. J Manuf Process 56:463-473

5. Dhar NR, Islam MW, Islam S, Mithu MAH (2006) The influence of minimum quantity of lubrication (MQL) on cutting temperature, chip and dimensional accuracy in turning AISI-1040 steel. J Mater Process Technol 171(1):93-99

6. Khan M, Mithu M, Dhar NR (2009) Effects of minimum quantity lubrication on turning AISI 9310 alloy steel using vegetable oil-based cutting fluid. J Mater Process Tech 209(15-16):5573-5583

7. Yldrm AV (2019) Investigation of hard turning performance of eco-friendly cooling strategies: Cryogenic cooling and nanofluid based MQL. Tribol Int 144:106127

8. Jawahir IS, Attia H, Biermann D, Duflou J, Klocke F, Meyer D, Newman ST, Pusavec F, Putz M, Rech J (2016) Cryogenic manufacturing processes. CIRP Annals-Manufacturing Technology

9. Nalbant M, Yildiz Y (2011) Effect of cryogenic cooling in milling process of AISI 304 stainless steel. Trans Nonferrous Met Soc China 21:72-79 
10. Ravi S, Kumar MP (2011) Experimental investigations on cryogenic cooling by liquid nitrogen in the end milling of hardened steel. Cryogenics 51(9):509-515

11. Kumar MDP (2011) Cryogenic turning of the Ti-6Al-4V alloy with modified cutting tool inserts. Cryogenics 51:34-40

12. Weinert K, Inasaki I, Sutherland JW, Wakabayashi T (2004) Dry Machining and Minimum Quantity Lubrication. CIRP Annals - Manufacturing Technology 53(2):511-537

13. Shokrani A, Al-Samarrai I, Newman ST (2019) Hybrid cryogenic MQL for improving tool life in machining of Ti-6Al-4V titanium alloy. J Manuf Process 43:229-243

14. Singh H, Sharma VS, Dogra M (2019) Exploration of graphene assisted vegetables oil based minimum quantity lubrication for surface grinding of TI-6AL-4V-ELI. Tribol Int 144(3-4):106113

15. Khan AM, Gupta MK, Hegab H, Jamil M, Mozammel M, He N, Song QH, Liu ZQ, Pruncu Cl (2020) Energy-based cost integrated modelling and sustainability assessment of Al-GnP hybrid nanofluid assisted turning of AISI52100 steel. J Clean Prod 257:120502

16. Şirin Ş, Kıvak T (2019) Performances of different eco-friendly nanofluid lubricants in the milling of Inconel X-750 superalloy. Tribol Int 137:180-192

17. YIdrm AV (2019) Experimental comparison of the performance of nanofluids, cryogenic and hybrid cooling in turning of Inconel 625. Tribol Int 137:366-378

18. Sirin S, Sarıkaya M, Yıldııım (2021) ÇV,Kıvak T. Machinability performance of nickel alloy X-750 with SiAION ceramic cutting tool under dry, MQL and hBN mixed nanofluid-MQL. Tribol Int 153:1066173

19. Shirakashi K (1965) International Organization for Standardization. J Text Machinary Soc 18(5):322-324

20. Dhar NR, Kamruzzaman M (2007) Cutting temperature, tool wear, surface roughness and dimensional deviation in turning AISI-4037 steel under cryogenic condition. Int J Mach Tools Manuf 47(5):754-759

21. Bermingham MJ, Kirsch J, Sun S, Palanisamy S, Dargusch MS (2011) New observations on tool life, cutting forces and chip morphology in cryogenic machining Ti-6Al-4V. Int J Mach Tools Manuf 51(6):500-511

22. Revuru RS, Posinasetti NR, Ramana V, Amrita M (2017) Application of cutting fluids in machining of titanium alloys-a review. Int J Adv Manuf Technol 91(5-8):2477-2498

23. Jia DZ, Li CH, Zhang YB, Yang M, Wang YG, Guo S, Cao H (2017) Specific energy and surface roughness of minimum quantity lubrication grinding Ni-based alloy with mixed vegetable oil-based nanofluids. Precision Eng - J Int Soc Precision Eng Nanatechnol 50:248-262

24. Lee I, Bajpai V, Moon S, Byun J, Lee Y, Park HW (2015) Tool life improvement in cryogenic cooled milling of the preheated Ti-6Al-4V. Int J Adv Manuf Technol 79(1-4):665-673

25. Hong SY, Markus I, Jeong WC (2001) New cooling approach and tool life improvement in cryogenic machining of titanium alloy Ti-6Al-4V. Int J Mach Tools Manuf 41(15):2245-2260 
26. Miranda A, Barekar N, McKay BJ (2019) MWCNTs and their use in Al-MMCs for ultra-high thermal conductivity applications: A review. J Alloys Compd 774:820-840

27. Sahu NK, Andhare AB, Raju RA (2018) Evaluation of performance of nanofluid using multiwalled carbon nanotubes for machining of Ti-6AL-4V. Mach Sci Technol 22:476-492

28. Turgay K (2014) Optimization of surface roughness and flank wear using the Taguchi method in milling of Hadfield steel with PVD and CVD coated inserts. Measurement 50:19-28

29. Yldrm AV, Kvak T, Sarkaya M, Irin E (2020) Evaluation of tool wear, surface roughness/topography and chip morphology when machining of Ni-based alloy 625 under MQL, cryogenic cooling and CryoMQL.Journal of Materials Research and Technology, 9(2)

30. Khanna N, Shah P, Chetan (2020) Comparative Analysis of Dry, Flood, MQL and Cryogenic $\mathrm{CO}_{2}$ Techniques during the Machining of 15-5-PH SS alloy. Tribol Int 146:106196

31. Dhar NR, Paul S, Chattopadhyay AB (2002) Machining of AISI 4140 steel under cryogenic coolingtool wear, surface roughness and dimensional deviation. J Mater Process Technol 123(3):483-489

32. Amrita M, Srikant RR, Sitaramaraju AV (2014) Performance Evaluation of Nanographite-Based Cutting Fluid in Machining Process. Mater Manuf Processes 29:600-605

33. Padmini R, Krishna PV, MohanaRao GK (2016) Effectiveness of vegetable oil based nanofluids as potential cutting fluids in turning AISI 1040 steel. Tribol Int 94:490-501

34. Kitagawa T, Kubo A, Maekawa K (1997) Temperature and wear of cutting tools in high-speed machining of Inconel 718 and Ti-6Al-6V-2Sn. Wear 202(202):142-148

35. Liang XL, Liu ZQ, Yao GH, Wang B, Ren XP (2019) Investigation of surface topography and its deterioration resulting from tool wear evolution when dry turning of titanium alloy Ti-6Al-4V. Tribology international. 135:130-142

36. Oliaei SNB, Karpat Y (2016) Investigating the influence of built-up edge on forces and surface roughness in micro scale orthogonal machining of titanium alloy Ti6Al4V. Mach Sci Technol 235:28-40

37. Zbek O, Saruhan H (2020) The effect of vibration and cutting zone temperature on surface roughness and tool wear in eco-friendly MQL turning of AISI D2. J Mater Res Technol 9(3):27622772

38. Sharma AK, Katiyar JK, Bhaumik S, Roy S (2019) Influence of alumina/MWCNT hybrid nanoparticle additives on tribological properties of lubricants in turning operations. Friction 7:153-168

39. Khanna N, Shah P, Zadafiya KR, Maruda R (2020) In-house development of eco-friendly lubrication techniques (EMQL, Nanoparticles+EMQL and EL) for improving machining performance of 15-5 PHSS. Tribol Int 151:106476

40. Ming Z, Wang X, Fu X, Xia Y (2009) Performance and anti-wear mechanism of $\mathrm{CaCO}_{3}$ nanoparticles as a green additive in poly-alpha-olefin. Tribol Int 42(7):1029-1039

41. Raju RA, Andhare A, Sahu NK (2017) Performance of multi-walled carbon nanotube-based nanofluid in turning operation. Mater Manuf Process 32:1490-1496 
42. Peña-Parás L, Maldonado-Cortés D, Taha-Tijerina J (2019) Eco-friendly Nanoparticle Additives for Lubricants and Their Tribological Characterization. 1: 3247-3267

43. Waikar RA, Guo YB (2008) A comprehensive characterization of 3D surface topography induced by hard turning versus grinding. J Mater Process Technol 197(1-3):189-199

44. Ndin O, Kvak T, Sarkaya M (2020) Investigation of the influence of MWCNTs mixed nanofluid on the machinability characteristics of PH 13-8 Mo stainless steel. Tribol Int 148:106323

45. Miranda A, Barekar N, McKay BJ (2019) MWCNTs and their use in Al-MMCs for ultra-high thermal conductivity applications: A review. J Alloys Compd 774:820-840

\section{Figures}
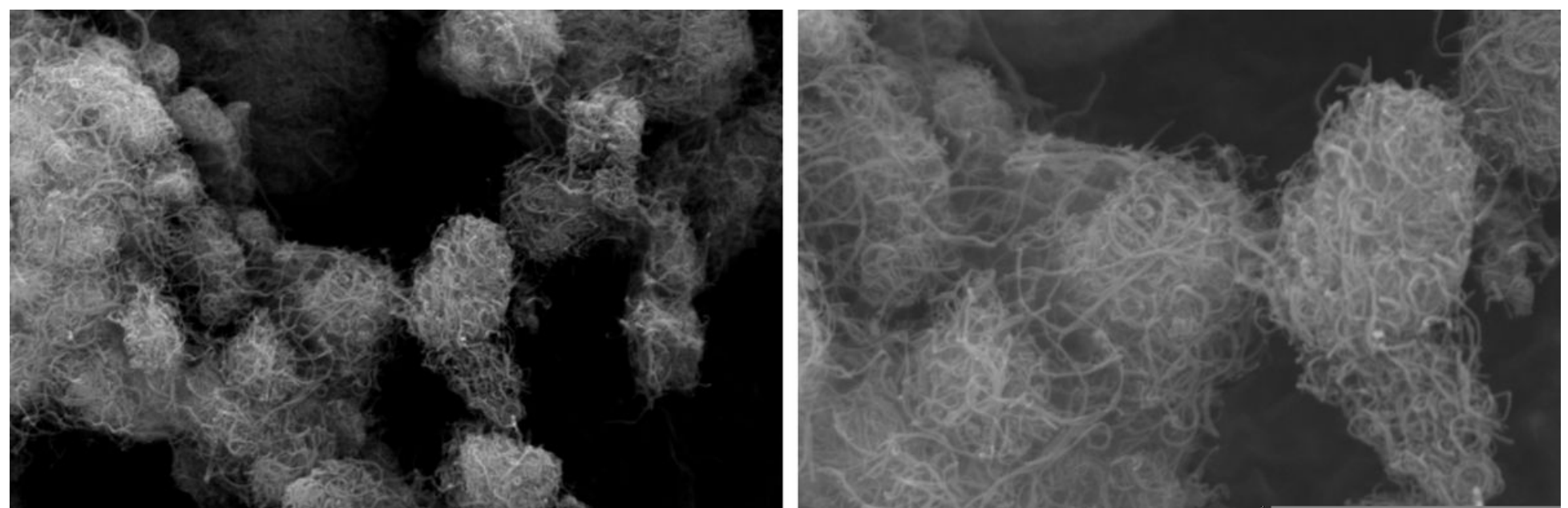

Figure 1 
Micromorphology of multi-walled carbon nanotubes at different magnifications under an electron microscope.

Figure 2

Complete experimental setup and process

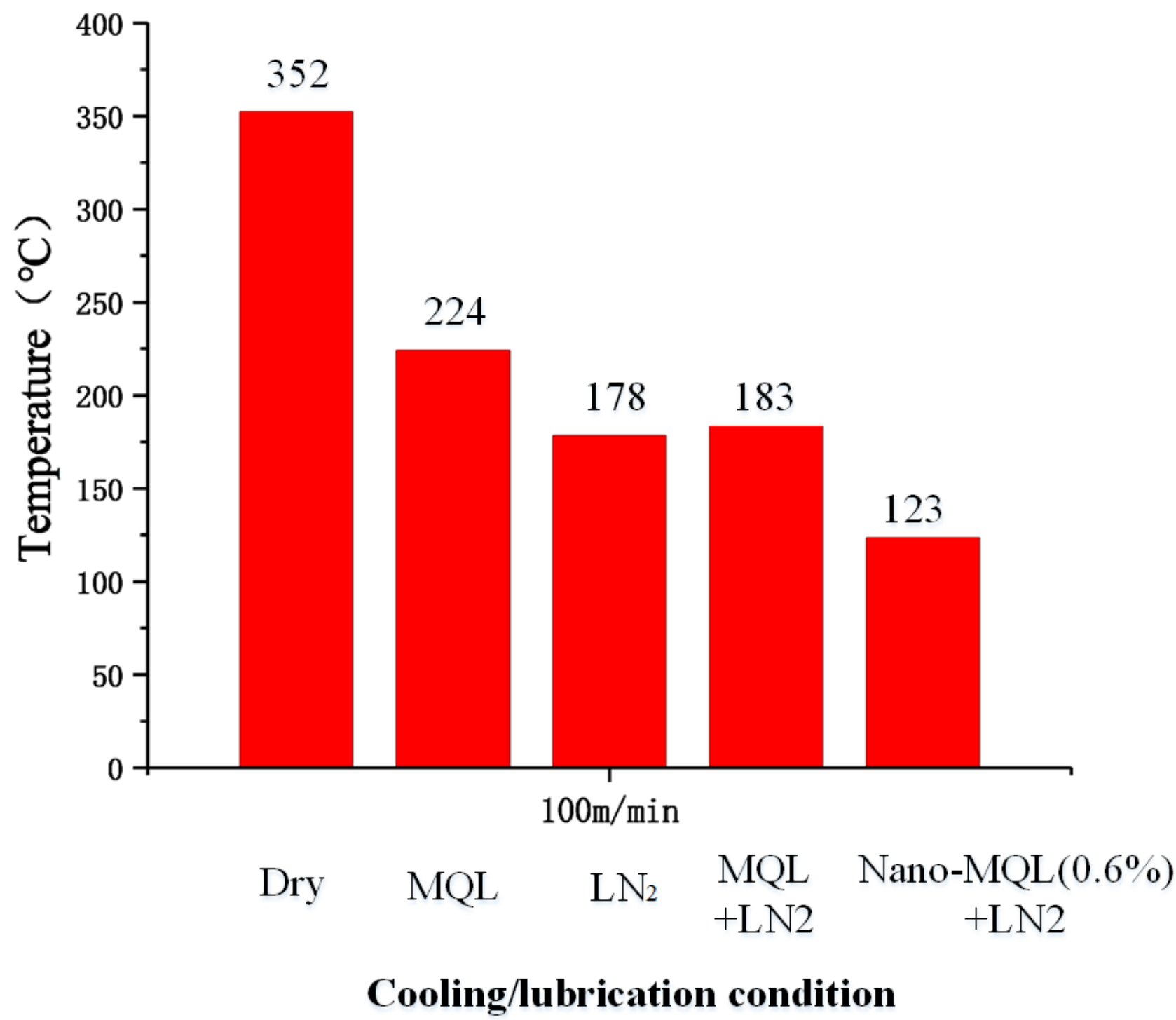

Figure 3 
Effect of cooling and lubrication methods on temperature

\section{Figure 4}

Optical image (a-e) and wear result (f) of the tool flank under different machining conditions.

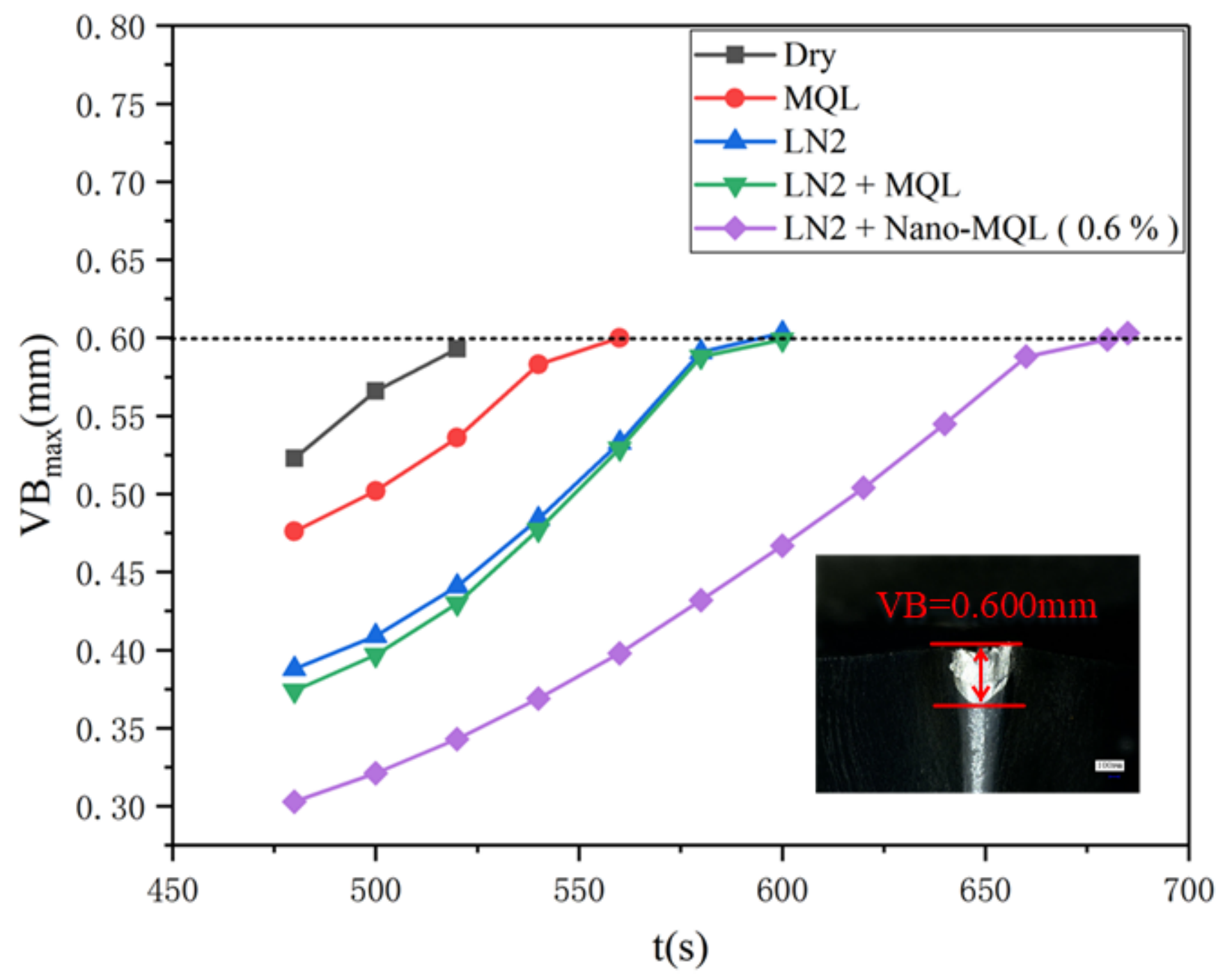

Figure 5

Changes of flank wear with machining time 
Figure 6

Electron microscope images of tool wear under different machining conditions

Figure 7

EDS element detection of tools under different machining conditions

Figure 8

Lubrication process of multi-walled carbon nanotubes 


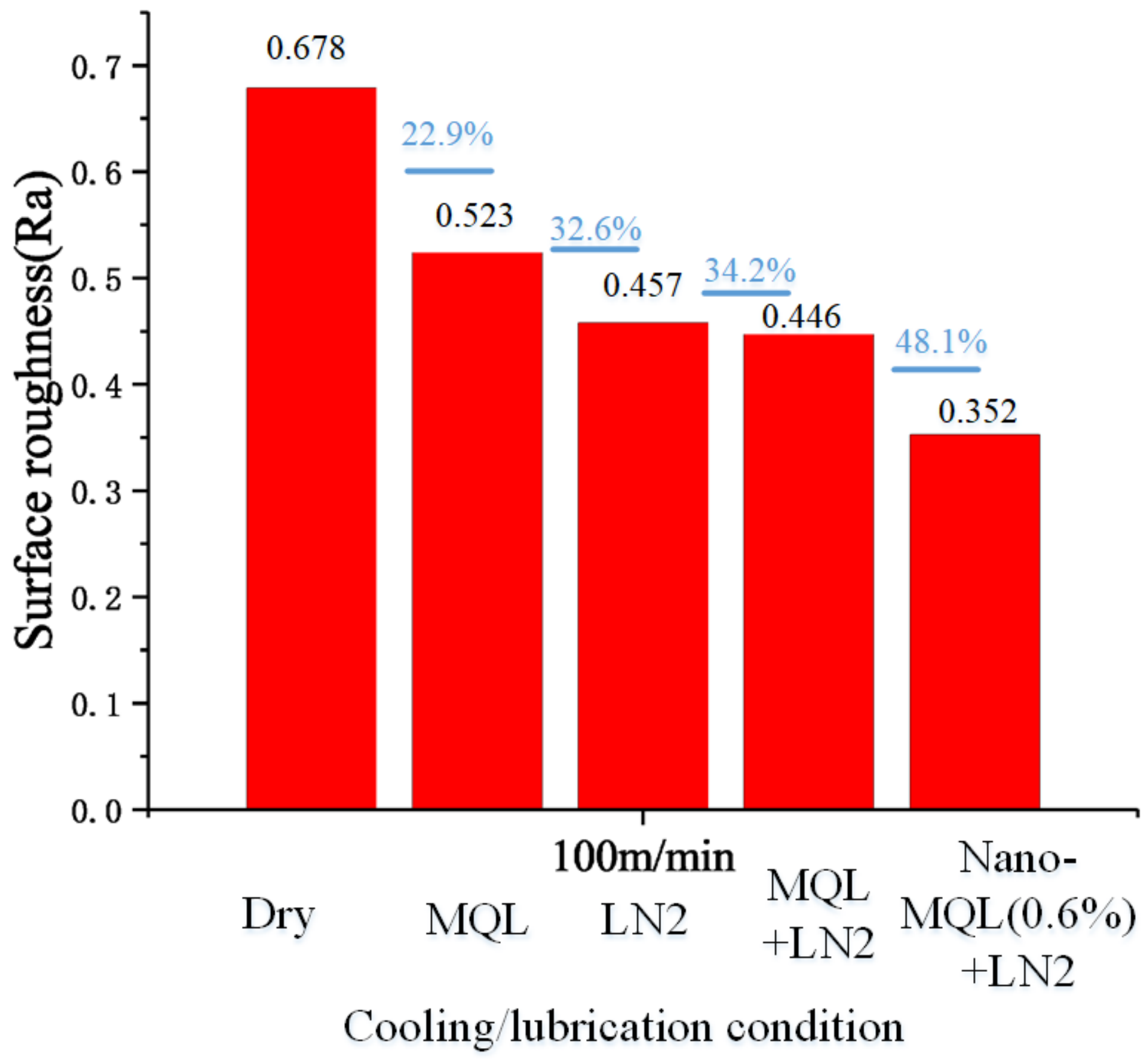

Figure 9

Effect of cooling and lubrication methods on the surface roughness 

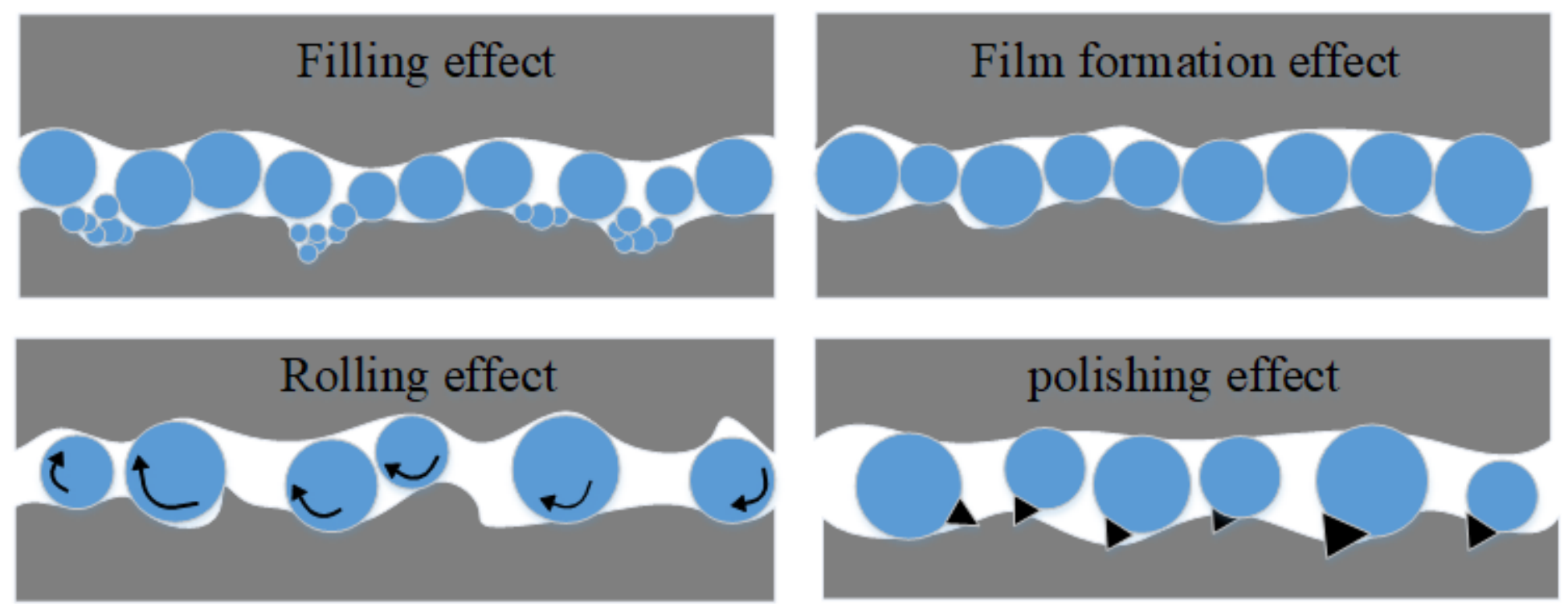

Figure 10

Four tribological effects of multi-walled carbon nanotubes.

Figure 11

Machined surface morphology under different cooling and lubrication conditions 